\title{
Universidade Popular Comunitária: a construção dos conhecimentos por meio das experiências simbólicas
}

\section{Popular Community University: the construction of knowledge through symbolic}

\author{
experiences
}

Loedilza Milicia da Silva

Doutoranda no Programa de Pós-Graduação em Educação

Universidade Federal de Mato Grosso

Mato Grosso, MT - Brasil

loedilza10@gmail.com

Luiz Augusto Passos

Doutor em Educação

Universidade Federal de Mato Grosso

Mato Grosso, MT - Brasil

passospassos@gmail.com

Resumo: A Educação de Jovens (EJA) e Adultos é formada, em sua maioria, por estudantes excluídos(as) do sistema educacional. Estes buscam uma educação que garanta o seu direito de aprender a aprender. A Universidade Popular Comunitária (UPC) surgiu para ser essa outra oferta educacional. Por meio das experiências simbólicas dos(as) estudantes e da comunidade, a UPC buscou construir um projeto inovador para a educação de jovens e adultos(as) da periferia cuiabana. Diante desse cenário, este artigo tem como objetivo abordar sobre algumas dessas experiências, mediante pesquisas bibliográficas, documentos oficiais, rodas de conversa e estudos apresentados na dissertação de mestrado desta autora, desenvolvida no período de 2019 e 2020 . Os resultados indicaram que os trabalhos com os relatos de vida dos(as) estudantes contribuíram para melhorar o aprendizado deles, além da elevação da autoestima e criticidade desse público.

Palavras chave: Universidade Popular Comunitária; educação de jovens e adultos; simbolismo; fenomenologia.

Abstract: Youth and Adult Education (EJA) is formed, in its majority, by students excluded from the educational system. They seek an education that guarantees their right to learn how to learn. The Popular Community University (UPC) emerged to be this other educational offer. Through the symbolic experiences of the students and the community, the UPC sought to build an innovative project for the education of young people and adults from the outskirts of Cuiabá, in Mato Grosso. On this scenario, this article aims to address some of these experiences, through bibliographic research, official documents, conversation wheels and studies presented in the master's thesis of this author, developed in 2019 and 2020. The results indicated that the work with the students' life stories contributed to improve their learning, besides the elevation of self-esteem and criticality of this public.

Keywords: Popular Community University; youth and adult education; symbolism; phenomenology.

Cite como

\section{(ABNT NBR 6023:2018)}

SILVA, Loedilza Milicia; PASSOS, Luiz Augusto. Universidade Popular Comunitária: a construção dos conhecimentos por meio das experiências simbólicas. Dialogia, São Paulo, n. 40, p. 1-19, e19645, jan./abr. 2022. Disponível em: https://doi.org/10.5585/40.2022.19645.

American Psychological Association (APA)

Silva, L. M., \& Passos, L. A. (2022, jan./abr.) Universidade Popular Comunitária: a construção dos conhecimentos por meio das experiências simbólicas. Dialogia, São Paulo, 40, p. 1-19, e19645. https:/ / doi.org/10.5585/40.2022.19645. 


\section{Introdução}

Este artigo emerge da necessidade de demonstrar parte dos resultados alcançados pela pesquisa de mestrado, a qual buscou compreender como se deu a atuação da Universidade Popular Comunitária (UPC), que foi uma forma diferenciada de ofertar a Educação de Jovens e Adultos (EJA) no município de Cuiabá (MT). Para tanto, a construção desta investigação é do tipo bibliográfica, pautada ainda na etnografia, a partir da análise de documentos oficiais, rodas de conversa e de estudos desenvolvidos que abordam a temática.

As coletas dos dados que subsidiaram a pesquisa principal ocorreram em três etapas. A primeira foi a leitura de referenciais teóricos, seguida de uma ampla pesquisa em documentos disponibilizados pela Secretaria Municipal de Educação de Cuiabá; na sequência, foi efetuada uma roda de conversa com três ex-alunos e quatro ex-professores que atuaram na UPC e, por fim, fezse a análise de todos os documentos e dados acessados.

$\mathrm{Na}$ roda de conversa, foi proposto aos participantes responder à seguinte pergunta-chave: que imagens e memórias the ocorrem quando ouve a palavra UPC? Durante três horas de um descontraído bate-papo, cada um, a seu modo, respondeu ao questionamento, cujas respostas foram capturadas por aparelhos de áudio e vídeo. Todos os instrumentos metodológicos utilizados obedeceram aos procedimentos éticos estabelecidos para a pesquisa científica em Ciências Humanas.

Após a coleta dos dados da roda de conversa, efetuou-se a busca por palavras significativas para o tema abordado como: autonomia, afetividade, vivência, diálogo, emancipação, respeito, prática libertária e diversas outras, que fizeram das práticas da UPC algo inédito, resultando em um apanhado de estudos e publicações o qual versou sobre as diferentes práticas desenvolvidas pela UPC e que auxiliou no desenvolvimento da pesquisa.

Assim, um dos focos iniciais foi buscar compreender as concepções sobre a educação dentro da UPC e a construção de saberes, além de agregar o entendimento sobre o simbolismo e a fenomenologia e como isso se verifica na vivência cotidiana, refletindo no processo educativo dos indivíduos.

\section{A Educação de Jovens e Adultos e a Universidade Popular Comunitária}

A Educação de Jovens e Adultos (EJA) é uma modalidade da educação básica que visa ao pleno desenvolvimento do ser humano, a qual prepara para o exercício da cidadania e qualificação para o mundo do trabalho. Esses são direitos expressos na Constituição Federal de 1988, conhecida como Constituição Cidadã, cujo nome foi dado por estarem incluídos em seu conteúdo de leis vários direitos básicos necessários para uma vida digna a todos os cidadãos, dentre os quais se 
destaca a educação, inclusive para aqueles que não tiveram acesso ao estudo em um outro período da vida, como é o caso das pessoas que buscam a EJA.

A aplicação prática de uma lei depende do cumprimento pelo poder público e do respeito deste com os cidadãos, cuja aplicabilidade deve ser cobrada nos casos omissos (ou inefetivos), assegurando, assim, o princípio da equidade e igualdade. Nesse sentido, Arroyo (2017, p. 93) afirma que "a diversidade de lutas pelo direito humano dos grupos sociais, raciais, sexuais, negados no direito a ter direito, são lutas por dignidade humana". No entanto, essa dignidade, durante muito tempo, foi negada para esses e outros grupos, que precisam cotidianamente lutar por algo que já está expresso em lei para garantir que os seus direitos, ainda invisibilizados, sejam respeitados.

A educação é um desses direitos negados, pois, conforme se observa na história educacional brasileira, em que pese a existência de várias premissas legais, ao longo do tempo, muitos estudantes foram e continuam sendo excluídos do seu direito à educação porque não se adequam à forma como a escola está organizada. Disso decorre o fracasso escolar, que se torna um instrumento de reiteração da exclusão, da divisão de classe e da formação de mão de obra barata, tipo "exército de reserva” de "mão de obra disponível', já apontado na literatura marxista.

[...] Fracassados escolares de um ensino que, de uma determinada "faixa salarial familiar" para baixo, funciona justamente através de fazer crianças e adolescentes trabalhadores passarem pela escola sem haverem nunca passado pela educação escolar, para que o seu trabalho adulto, subalterno, seja o de quem aprendeu sem tempo de tirar do saber do estudo o proveito que torne dignos o trabalho e a vida. (BRANDÃO, 2006, p. 26, grifos do autor).

Diante desse cenário, esses excluídos buscam na Educação de Jovens e Adultos uma forma de compensar o tempo perdido e, ao retornarem à escola, eles esperam encontrar algo diferente, não apenas mudanças físicas no local, mas um novo modo de acolhê-los, de construir os currículos e de direcionar o processo de ensino e aprendizagem.

Quando esses estudantes não encontram uma metodologia diferenciada - envolvente e fascinante - que os estimule a permanecerem na escola, após um dia de trabalho pesado, eles não conseguem, mais uma vez, se sentirem inseridos no contexto educacional para concluírem seus estudos. Essa situação, provavelmente, é uma das causas de a EJA ainda apresentar um elevado índice de reprovação, desistência e evasão. A busca por novas metodologias para atender a essa demanda torna-se necessária em todo o país, especialmente quando se trata de acabar efetivamente ou de, pelo menos, reduzir a prática de exclusão de alguns estudantes do sistema escolar.

O currículo demanda, para essa modalidade, uma constante construção, ou seja, não pode vir pronto. É imperioso que esse seja construído ao longo do processo, costurado pelas mãos de 
todos(as) os(as) envolvidos(as). Merleau-Ponty (2006) defende esse currículo construído no decorrer do processo, abrindo para possibilidades infinitas de arranjos e rearranjos, uma vez que se trata de uma ferramenta dinâmica, aberta e inconclusa por natureza.

A Universidade Popular Comunitária (UPC) foi uma forma diferenciada de ofertar a Educação de Jovens e Adultos (EJA), no município de Cuiabá, entre os anos de 2002 e 2010. Essa prática teve início a partir do diálogo estabelecido entre os(as) dirigentes da Secretaria Municipal de Educação de Cuiabá (SME) e os(as) diversos(as) educadores(as) que atuavam na modalidade da EJA, os(as) quais buscavam por outras experiências exitosas para as pessoas que optavam por essa modalidade como uma proposta educativa que, de fato, atendesse às necessidades do ciclo de vida da pessoa adulta.

A ideia de universidade, para Maldonado (1995), sempre compôs o pensamento de se tratar do lugar no qual os(as) adultos(as) estudam, caso estes(as) tivessem tido acesso ao processo de escolarização em idade própria (na infância). Ainda de acordo com o entendimento desse autor, a universidade deve ser pensada e concebida a partir de um contexto que permita um processo de ensino, pesquisa e extensão no intento de construir um conhecimento que pode ser socializado e utilizado pela comunidade no campus onde as pessoas estão inseridas e, nele, o trabalho coletivo de produção pode dar aporte à subsistência com renda do trabalho associado (MALDONADO, 1995).

As pesquisas realizadas pela equipe da Secretaria Municipal de Educação de Cuiabá, em 2002, demonstraram a existência de uma grande quantidade de pessoas jovens e adultos(as) analfabetos(as) ou com pouca escolarização, principalmente nos bairros da periferia da capital cuiabana. Nas justificativas apontadas à época, registrou-se que as ações governamentais anteriores àquele período (2002), como as de hoje (2020), não deram conta de suprir essa necessidade, sendo essa a principal motivação para a criação da UPC.

Foi realizada uma ampla pesquisa para construir essa oferta diferenciada em bairros da região sul da capital cuiabana. Diagnosticou-se a existência de uma grande demanda de população adulta, que, principalmente, tinha interesse em voltar a estudar, porém buscava uma escola que não fosse apenas repassadora de conteúdo, mas que a despertasse para uma educação pautada na construção de saberes. Como afirma Freire (1987, p. 18), "alfabetizar não é aprender a repetir palavras prontas, mas a dizer as suas próprias palavras, e que tenham significado para quem diz e para quem ouve."

A partir da tabulação das pesquisas realizadas nos bairros periféricos, ficou evidente a necessidade de um currículo próprio e de metodologias pedagógicas diferenciadas para a EJA. A 
Universidade Popular Comunitária buscou, com isso, construir seu fazer pedagógico baseado nas histórias de vida de seus estudantes, em seus sonhos, nos desejos e envolvimento da comunidade. Essa forma de atuação é corroborada por Santos e Menezes (2010, p. 15): “Toda experiência social produz e reproduz conhecimentos e, ao fazê-los, pressupõe uma ou várias epistemologias”. Esses vários conhecimentos válidos ou epistemologias ajudam a construir saberes significativos para os(as) estudantes, pois fazem parte da sua construção.

A UPC, por meio de um "Cardápio de Saberes", como era chamado esse aspecto do seu currículo, rico em experiências sociais e individuais, buscou construir tudo pelas mãos de todos(as) - educadores(as) e educandos(as) — em um processo dinâmico de troca de saberes e questionamentos sobre o papel de cada um na sociedade, na política, no seu pensar e em seu viver. Merleau-Ponty (2006, p. 3) afirma que: “Tudo aquilo que sei do mundo, mesmo por ciência, eu sei a partir de uma visão minha ou de uma experiência do mundo sem a qual os símbolos da ciência não poderiam dizer nada". O envolvimento dos(as) estudantes no seu processo de aprendizagem e na construção de uma sociedade mais justa e igualitária parece ser a receita para a criação de uma outra educação e de um outro mundo.

Isso demonstra a importância do envolvimento coletivo, que era a marca da UPC, o qual levou, inclusive, à escolha das denominações de artisentis $^{1}$ para designar os(as) professores(as) e de coartisentis $^{2}$, os(as) estudantes. Para Merleau-Ponty (2004, p. 20), são as experiências humanas que conferem uma certa significação emocional, tornando-se compreensíveis para todos(as) os(as) envolvidos(as).

Os(as) professores(as) não deveriam, nessa perspectiva, ser aqueles(as) que se julgavam detentores(as) de todo o conhecimento, mas, sim, um(a) parceiro(a) na construção dos saberes, com arte e amor, e que os(as) estudantes, como colaboradores(as) e coartisentis, deveriam se sentir envolvidos(as), participando ativamente dessa construção.

Essa parceria e envolvimento entre artisentis e coartisentis quebrou com a hierarquia tradicionalmente existente nas escolas. Na UPC, todos(as) faziam tudo, desde a limpeza do local das aulas, a construção do currículo, até a prestação de contas. Não havia marginalização de conhecimento e nenhum saber era pensado fora da vivência do(a) estudante e da comunidade. Por isso, a UPC deu resultado, tendo em vista que reconheceu o que antes era excluído.

\footnotetext{
1 "Artisentis - Profissionais com habilidade e saberes adquiridos pelos estudos e ou pela prática que exercitasse uma memória coletiva de ser e de agir na qual o fazer da arte e da indústria os levam a práxis de criação permanente de procedimento e sentidos (plural: artisentis). Artisentis; arte e sentimentos. Arte- conhecimento, criação. Sentir, sentido, ser sensibilidade, emoção. Profissional da arte do ser.” (PDI, p. 3)

2 “Coartisentis - pessoas que por disposição própria principia-se nas atividades caracterizadoras, dos fazeres de artisentis, recebendo e passando saberes, atuando como artífice, auxiliantes (plural: coartisentis). Coartisentis, aquele que faz com, compartilha com o artisentis o fazer, o sentir, a vida" (PDI, p. 3)
} 
Reconhecer e enfatizar a relação estreita entre experiências e conhecimento ou reconhecer que todo conhecimento tem sua origem na experiência social, não é apenas uma questão epistemológica a ser estudada nas teorias da produção de conhecimento. É um pré-requisito para entender por que as vivências dos educando e educadores, as experiências de luta, do trabalho e das condições docentes são desprestigiadas e ignoradas, não apenas no currículo, mas também na política de valorização profissional. (ARROYO, 2019, p. 117)

Esse desprestígio tem como objetivo manter o status quo e a dominação sobre as camadas populares para que estas continuem pensando que seu saber é menor que o conhecimento científico da classe dominante, de modo que, com isso, continuem valorizando o que vem de cima e o que é dos outros (de fora) e não o que é compartilhado e construído na comunidade.

Os saberes práticos das pessoas foram sendo construídos por meio de anos de vivências e experiências no núcleo familiar e comunitário. Eles expressam o modo de vida, a forma como observam as coisas do mundo vivido, a relação com a natureza, a religiosidade, a observação dos astros que influenciam nas suas colheitas e plantio, além do culto aos antepassados. Tudo isso tem um grande valor simbólico para todos(as) os(as) envolvidos(as) naquele núcleo e, por isso, quando a escola considera esse conhecimento, o(a) estudante também se sente respeitado(a), porque percebe que o seu saber tem valor. A dimensão sagrada é um elemento que potencializa o sentido em conformidade com a tradição popular, que liga cada pessoa a um coletivo que lhe dá sentido e existência.

\footnotetext{
Eu achava muito interessante a riqueza da proposta que foi a UPC, que não é só o contexto de comunidade, nós valorizávamos tudo que os estudantes sabiam, foi tudo tão rico, que, às vezes, a gente nem entende direito o que foi esse processo. Achava interessante que os próprios coartisentis entraram no processo da construção de saberes e se a UPC tivesse dado certo, como as coisas seriam diferentes e a riqueza que teriam construído. (SILVA, Salvador Flavio Pereira: artisenti. Roda de conversa, 7 de mar.2020)
}

A EJA necessita de ter esse olhar abrangente e de totalidade, tornando-se não apenas uma educação de e para jovens e adultos(as), mas que seja abrangente, entusiasmante, criativa e popular. Brandão (2006) afirma que a educação popular tem esse valor de envolver e despertar para uma educação da comunidade, que busca novos conhecimentos e possibilidades de tornar o cidadão autônomo, criativo e crítico por sua condição de sujeito no mundo.

A experiência desenvolvida na UPC demonstrou que é possível uma EJA diferente. Uma educação que não carrega nada pronto e acabado para a sala de aula, mas que busca construir um currículo articulado entre os diversos saberes da vida de cada pessoa, em busca de um 
conhecimento mais complexo e abrangente, que pode ser utilizado no cotidiano da vida dos(as) estudantes e que faça sentido para a reconstrução de uma sociedade mais justa e humana.

\section{A construção dos saberes}

Somos seres inacabados, diferentes das outras espécies que já nascem prontas, sendo dirigidas ou guiadas instintivamente por toda a vida. Por sermos humanos(as), vamos nos construindo e reconstruindo com o tempo e as experiências, por meio das relações familiares, sociais, culturais, dos costumes e tradições que se reciclam e recriam (FREIRE, 1987).

Como seres inconclusos(as), somos abertos(as) ao aprendizado, que pode ocorrer nas mais diversas formas e lugares, porém jamais no isolamento e sem se relacionar. Freire (1987) afirma que os homens e mulheres se educam mutuamente em um constante envolvimento e troca entre si e os objetos. Essa inter-relação faz indivíduos(as) crescerem e adquirirem conhecimentos inéditos. Merleau-Ponty (2006) aprofunda a relação dizendo que não existe um polo da dialética sem o outro. Eles se abraçam. Conhecer é aprender na relação tensiva que nos produz como diferença.

Segundo a Teoria Geral do Conhecimento, defendida por Hessen (2003, p. 21), "No conhecimento defrontam-se consciência e objeto, sujeito e objeto. O conhecimento aparece como uma relação entre esses dois elementos”, mas essa relação não poderá ser de mão única, de um sujeito ativo e um objeto passivo, é necessária uma reciprocidade para que o conhecimento emerja.

Aprendendo com tudo, com todos(as) e em qualquer lugar, ainda é na escola o lugar em que esses saberes e conhecimentos são melhores estruturados e socializados de uma forma coerente e dinâmica, a depender da relação que se estabelece de atenção, carinho, criação e grandeza. O espaço escolar ainda é, para a maioria, um espaço de conhecimento e de alegria.

Merleau-Ponty (2004, p. 16) diz: “[...] que a nossa relação com o espaço não são as de um puro sujeito desencarnado com um objeto longínquo, mas as de um habitante do espaço com seu meio familiar". Essa familiaridade com o espaço escolar produz um sentimento de pertença para muitos(as), mesmo que, infelizmente, é sabido que a escola ainda relegue muitos conhecimentos populares e valorize mais aqueles ditos científicos impostos como os mais importantes pelas classes dominantes.

Apesar dos dilemas da escola, ela é um lugar de muita socialização, espaço no qual as pessoas circulam e podem compartilhar conhecimentos de diversas formas: pela interação com um livro didático ou de história; com um filme ou documentário; com os saberes dos(as) professores(as) e dos(as) colegas, que trazem conhecimentos variados da cultura familiar e 
comunitária ou, até mesmo, interagindo no próprio ambiente escolar, enfim, reunindo sujeitos(as) e objetos mediadores que são favoráveis ao desenvolvimento do conhecimento.

A escola não se mostra, ainda, voltada para a valorização dos saberes populares, aqueles que se aprendem na família e na comunidade, perpetuando, dessa forma, os processos educativos repetitivos e inertes, nos quais se acredita que os conhecimentos "eruditos" são mais ricos e carregam significados maiores que os populares. Os primeiros — saberes populares — pertencem ao nosso mundo vivido.

Muito professores ainda não refletem sobre sua prática, acabam apenas repassando o que é imposto pelo método tradicional, de cima para baixo. Por isso se mostra interessante a indagação lançada por Streck (2006, p. 108): “quem forma os educadores e onde eles são formados?”. Essa pergunta leva à reflexão sobre a supremacia da classe dominante, uma vez que é ela quem dita as regras na sociedade, nas escolas, faculdades e mídia. Por conta disso, nós, educadores, acabamos repassando e perpetuando práticas discriminatórias, reducionistas, não coletivas, alienantes, entre outras, que não possibilitam aos nossos estudantes refletirem sobre a sua condição de oprimido.

Mediante práticas de uma educação popular dialógica e reflexiva, Paulo Freire, em seu método de alfabetização, preconizou pela necessidade de que o processo de ensino e aprendizagem se desse a partir da construção de um saber com significados para os(as) aprendizes, por meio das concepções e palavras geradoras, ou seja, aquelas do mundo cotidiano dos(as) educandos(as), repletas de significados para eles, ultrapassando o silenciamento que se via aplicado no método tradicional de ensino. Essa nova maneira de ressignificar as palavras advindas das dores, dos suores e das essências emancipatórias deram sentido ao método freireano de ensino e o tornou famoso.

Apesar de se tratar de um modelo de ensino reconhecido, a alfabetização proposta por Freire ainda é pouco utilizada em nosso país, pois não é esse o método que o Estado defende. Majoritariamente, querem um saber já feito, pronto e engessado, voltado para a formação de sujeitos(as) alienados(as), que desconhecem os seus direitos, de modo que eles(as) não podem dominar e compreender o sentido do que pensam, dizem e escrevem.

Existimos dentro de um mundo social onde senhores do poder, através do Estado, decidem e definem para os "outros" (para nós) o que querem que seja a relação entre eles e os "outros" (nós). Vivemos em uma sociedade onde um Estado de democracia restrita não é o lugar coletivo do poder consensual de criar direitos, de criar por consenso as normas da vida coletiva, mas apenas é o lugar de obedecê-las. (BRANDÃO, 2006, p. 5)

Essa obediência cega leva muitas Secretarias de Educação, gestores e professores a reproduzirem apenas o tipo de educação ditado pelo Estado, como se este fosse a única forma possível da informação fazer sentido. Não param para pensar nas infinitas possibilidades e arranjos 
educativos que podem facilitar o aprendizado dos(as) estudantes, começando pela valorização dos saberes individuais e coletivos da comunidade onde a escola está inserida.

Dar significado aos conhecimentos significaria, primeiramente, apresentar ao sujeito os objetos familiares, de modo que, por meio deles, o(a) aprendiz consiga ancorar o novo que está sendo ensinado ao que já existe no nosso campo semântico associativo e conceitual, para que o conhecimento aconteça em um patamar interativo de recriação.

A Universidade Popular Comunitária (UPC) utilizou a Teoria do Conhecimento de Hessen (2003) na construção do seu arcabouço metodológico e, de uma forma dinâmica e participativa entre sujeito e objetos, buscou construir conhecimentos sólidos, significativos, desejados e sonhados. Ela surgiu em torno de um projeto inovador, que rompeu com os paradigmas existentes nos quais o(a) professor(a) era o(a) único(a) sujeito(a) ativo(a) e os(as) estudantes eram todos(as) passivos(as). Como não havia relação entre sujeito(a) e objeto no antigo modelo, cada qual era, de certa forma, dotado de finalidades que não se correspondiam: os(as) estudantes começavam e desistiam; não havia uma relação dialética ou dialógica que levassem a uma construção com princípio, meio e fim, indissociáveis.

$\mathrm{Na}$ UPC, uma das marcas era a horizontalidade por meio de uma constante troca de conhecimentos entre professores(as) e estudantes, em que sujeitos(as) e objetos se relacionavam em uma forma dinâmica, possibilitando que os novos saberes fossem construídos sem espaços estanques que dissociassem os(as) envolvidos(as), de forma que o produto representasse a todos(as).

Essa outra dinâmica na construção do conhecimento desenvolvido pela UPC só foi possível porque, em 2002, a cidade de Cuiabá integrou a Associação Internacional das Cidades Educadoras (AICE). As cidades que se filiavam a essa associação se comprometiam em desenvolver ações para que toda a cidade se transformasse em um espaço educativo. Nesse período, estava à frente da Secretaria Municipal de Educação o professor Carlos Alberto Reyes Maldonado, intelectual visionário e com concepções de vida, movimentos sociais e educação incomuns. Ele buscou, junto com outros(as) profissionais da educação, criar uma forma diferente de ofertar a Educação de Jovens e Adultos (EJA) para a população da periferia da capital cuiabana, de maneira que respondesse aos sonhos de cada um.

A UPC valorizou os conhecimentos populares e eruditos de forma que nenhum deles se sobressaiu isoladamente. Por meio de práticas de reciprocidade e respeito, os saberes eram construídos pelas mãos de todos(as) os(as) envolvidos(as) sem se divorciar do fluxo constante que forma a vida. O envolvimento era um dos conceitos-chave da UPC, pois esta acreditava que, ao 
envolver todos(as) - professores(as), estudantes e comunidade - no processo de ensino e aprendizagem, a transformação seria coletiva.

As experiências realizadas pela UPC tinham como premissa a mais antiga universidade do mundo: a Universidade de Bolonha — instituída na cidade italiana de Bolonha no ano de 1088 , na qual o ensino era realizado a partir do desejo dos(as) estudantes, que, junto com os(as) professores(as), definiam "como", “quando" e “onde” a aprendizagem ocorreria. Na UPC também era assim, os(as) estudantes deliberavam o que estudar partindo de um consenso com os(as) professores(as). Era eleita a criação de um produto, que era produzido cooperadamente por todos(as) e deveria gerar renda ou ajudar a comunidade de alguma forma. A partir daí, todo o conhecimento era construído com o intuito de desenvolver aquele produto da melhor forma, mediante o uso das habilidades e competências que cada um foi adquirindo ao longo da vida, na troca de saberes.

\section{$4 \mathrm{O}$ simbolismo e a fenomenologia}

No poema 66 do TAO TE CHING, o livro do Caminho e da Virtude, escrito por Lao Tse ${ }^{3}$, que foi um dos grandes representantes do taoísmo chinês, tem uma passagem interessante que diz o seguinte:

O que pode tornar os rios e mares reis dos cem vales

É saber situar-se embaixo;

Por isso, podem ser os reis dos cem vales. (TSE, s.d.)

O simbolismo dessas palavras nos remete ao fato de que as coisas e as pessoas que estão na posição de baixo, como os rios e os mares, têm uma grande influência sobre o que está em cima, mesmo que, às vezes, essa pessoa não saiba ou não sinta esse poder.

Ao remeter essa passagem às formas atuais de viver, é possível observar que a maneira do agir de hoje tem forte influência das construções simbólicas que foram sendo constituídas ao longo da vida. Pode-se tomar, como exemplo, as questões religiosas: quando uma pessoa católica entra em uma igreja e faz o sinal da cruz, em uma ação simbólica que representaria a Cruz de Cristo Aquele que redimiu "os nossos pecados" —, é bem provável que tal representatividade foi aprendida na infância ao observar os(as) mais velhos(as). Por meio dessa ação, o(a) indivíduo(a) se

\footnotetext{
3 Lao Zi ou Laozi foi um filósofo e escritor da Antiga China. É conhecido por ser o autor do importante livro Tao Te Ching, fundador do taoísmo filosófico e uma divindade no taoísmo religioso e nas religiões tradicionais chinesas.
} 
sente protegido(a), ainda que, por muitas vezes, nem se pense nisso, pois o ato acontece de forma automática. Contudo, o simbolismo já está internalizado no indivíduo e opera significando o gesto.

Assim como a nossa vivência está impregnada de ações simbólicas, ela também nos ajuda a entender o mundo à nossa volta. Dessa forma, seria importante resgatar as práticas que todos(as) trazem das suas vivências e que dão o suporte à construção de novos conhecimentos, já que estes ocorrem da relação entre o(a) sujeito(a) e o objeto. A partir dessa concepção, pode-se construir um aprendizado mais prazeroso, efetivo e significativo. Merleau-Ponty (2006, p. 3) corrobora esse entendimento ao afirmar que: "Todo o universo da ciência é constituído sobre o mundo vivido $[\ldots] "$.

Cada pessoa tem histórias que constituíram e marcaram suas vidas. E os(as) estudantes da UPC não eram diferentes. Tratava-se de homens e mulheres, trabalhadores(as) que já tinham, em média, idade acima de 25 anos, com uma vida de muitas lutas e sofrimentos. Isso demonstrava o enorme potencial de conhecimentos e contribuições que esses poderiam oferecer na construção de novos saberes para todos(as).

Quando se fala em conhecimento simbólico, busca-se dar sentido a algo que vai além do significado manifestado, pois, muitas vezes, esses conceitos e símbolos estão enraizados no submundo do ser, mas têm grande poder sobre as vidas, que, se trabalhados de forma equilibrada, podem levar a novas atitudes, conhecimentos e ações que culminarão em dar outro sentido à existência. Para Santos (2008, p. 157-58), “[...] todos os conhecimentos sustentam práticas e constituem sujeitos".

Toda vida é simbólica. Usam-se símbolos para representar o que, às vezes, não se consegue expressar, como já apresentado em relação às religiões, quando se referem à imagem de um ser superior. Sem símbolos não se consegue atingir esse objetivo: alcançar uma noção de uma entidade suprema, ainda assim, o símbolo é uma incursão velada de uma realidade que se apalpa. Sem o simbolismo, a vida seria meramente racional e perderia a possibilidade de contemplar o ser fenomenológico e transcendental que todos(as) somos.

Ao afirmarmos que somos seres fenomenológicos podemos buscar suporte nos estudos da fenomenologia, que foi discutida por diversos pensadores e filósofos, como Husserl, Heidegger e Merleau-Ponty. A fenomenologia é uma filosofia que parte do mundo que já existe antes de qualquer reflexão e de qualquer pensamento que o situe.

Nesse contexto, embasamo-nos na fenomenologia merleau-pontyana que busca um reencontro com o mundo e com as pessoas, pelo mergulho no simbólico, na visibilidade possível, e na tangencialidade do imaginário. 


\begin{abstract}
A fenomenologia é o estudo da essência, e todos os problemas, segundo ela, resumemse em definir essência: a essência da percepção, a essência da consciência, por exemplo. Mas a fenomenologia é também uma filosofia que repõe a essência na existência, e não pensa que se possa compreender o homem e o mundo de outra maneira senão a partir da facticidade ${ }^{4}$. (MERLEAU-PONTY, 2006, p. 1).
\end{abstract}

Segundo Santo Agostinho, todos(as) possuem a essência de Deus, e, como seres divinos(as) e transcendentais, pode-se pensar esse mundo como um ser encarnado e vivendo sua essência, mas, para isso, é preciso se conhecer e refletir sobre o que cada indivíduo representa; e, isso só se mostra possível por meio de uma educação que não seja alienante, mas que, ao contrário, proporcione a liberdade de pensamentos e escolhas. A UPC, nesse sentido, não tinha como premissa apenas a educação de jovens e adultos(as) tradicional; ela buscava e idealizava uma educação de base popular, a serviço de um trabalho simbólico e político de transformação da ordem social dominante (BRANDÃO, 2006).

A Universidade Popular Comunitária foi constituída com a premissa de uma educação popular. Criada pela Prefeitura Municipal de Cuiabá, sob a Lei n. ${ }^{\circ}$ 4.325, de 26 de dezembro de 2002, teve por base a Resolução n. ${ }^{\circ}$ 003/2002 do Conselho Municipal de Educação (CME) e funcionou com cinco campi nos mais diversos bairros periféricos da capital. Ofertou cursos desde a alfabetização até o ensino médio, no entanto, não conseguiu concluir seu objetivo inicial, o qual previa também a oferta de cursos de graduação e pós-graduação, uma vez que foi projetada para ser uma universidade pública e gratuita com um contorno diferenciado, no sentido que os cursos de graduação e pós-graduação seriam coletivos e deveriam atender à demanda da comunidade.

Ao objetivar a oferta do ciclo formativo completo: da alfabetização à pós-graduação, a UPC buscava romper com o paradigma de que a universidade era apenas para cursos superiores. Apesar do nome "universidade", no senso comum, estar relacionado à ideia acima, o objetivo original era trazer a ideia de ser universal, para todos(as) aqueles(as) que quisessem concluir os seus estudos, e não apenas para a elite que, normalmente, já possui acesso ao ensino superior.

A UPC funcionou plenamente de 2002 a 2006 e foi completamente fechada em 2010. Seu fechamento decorre da mudança do prefeito da capital cuiabana em 2006, que não via necessidade de o município ofertar o ensino superior devido aos gastos gerados e em face da dificuldade de compreender o modelo educativo diferenciado que era proposto na UPC. Essa atitude deixa transparecer que sua administração estava mais preocupada com as questões de ordem financeira e com a possibilidade de eventuais desgastes políticos do que com um modelo de educação que estava dando resultado, cuja ideia é ratificada por Merleau-Ponty (1991, p. 2): “o sistema capitalista

\footnotetext{
${ }^{4}$ Por facticidade se deve entender a condição plena do sujeito no mundo, atingido pelo conjunto de condições ou determinações, inclusive aquela de não ter escolhido esta condição; segundo Sartre (1905-1980), condenado à existência e à liberdade, que não escolhi. Facticidade é todo contexto, do qual há caminhos a acolher, e até, eventualmente, ser condenado a ser livre.
} 
põe a economia acima do humano e que não se preocupa se as pessoas morrem em guerras ou em cidades sem estrutura, o que importa mesmo é o ganho do capital."

\title{
5 O simbolismo da vida vivida
}

Os homens e as mulheres que participaram da Universidade Popular Comunitária, assim como o restante da população mundial, possuíam uma vida rica em simbolismos. E os(as) professores(as) artisentis conseguiram, de uma forma brilhante, utilizar esses conhecimentos de uma vida vivida na construção de um processo de ensino e aprendizagem significativo. Essa concepção encontra suporte nos ideários de Merleau-Ponty e Freire, para quem todo o universo da ciência é construído sobre o mundo vivido, que são as experiências, algo que os(as) estudantes e professores(as) tinham de sobra.

Os currículos vivos foram erigidos a partir das diversas vivências de todos(as) os(as) envolvidos(as). Essas histórias deram suporte às trocas de experiência que culminavam em aprendizagem na UPC.

Passo a relatar, a seguir, algumas aprendizagens que foram mais significativas, segundo os(as) professores(as) entrevistados(as):

\begin{abstract}
O senhor Sebastião era alcoólatra e tinha alguns problemas, mas era uma pessoa muito interessante. Ele era alto, negro, ele veio do Rio Grande do Sul, foi criado em uma comunidade alemã, ele não sabia ler, mas tinha um grande conhecimento de mundo e falava bem o alemão. Passamos a trabalhar a história do Brasil, a partir da história de vida do seu Sebastião. Em 1940, ele trabalhava na fazenda de Getúlio Vargas. Quando ele começou a escrever, ele escrevia tudo junto e aí eu ia lendo para ele e dizendo: "olha, seu Sebastião, aqui tem um espaço entre as palavras!" Ele observava a fala e ia aprendendo, ele era muito esforçado. (SILVA, Maria de Fátima: artisenti. Roda de conversa em 7 de mar. 2020)
\end{abstract}

Esse relato demonstra a quantidade de simbolismos que essa vida carregava e de que forma os(as) artisentis perceberam e utilizavam esse conhecimento, pois "a ciência não tem e não terá jamais o mesmo sentido de ser que o mundo percebido [...]” (MERLEAU-PONTY, 2006, p. 3). Em entrevista com os(as) professores(as) que atuaram na época, foi relatado que, da história de vida do senhor Sebastião, foi possível trabalhar com todas as disciplinas e que, para além dessas experiências, outras iam se aglutinando na construção dos saberes coletivos.

Reconhecer que esses saberes populares são importantes na construção da aprendizagem abre uma enorme possibilidade de arranjos curriculares mais eficazes, capazes de manter os(as) estudantes na escola e de construir um outro modelo educacional mais justo, na medida em que este consegue se ver no currículo, como afirma Merleau-Ponty (2006, p. 4): “[...] antes de tudo um 
mundo se dispõe em torno de mim e começa a existir para mim [...]”. Freire (1987, p. 10) também corrobora com essa ideia, à medida que diz que "o sentido mais exato da alfabetização é que os estudantes aprendam a escrever a sua vida."

Outro relato extremamente simbólico e, ao mesmo tempo, significativo ocorrido na UPC foi referente às questões religiosas e de envolvimento de professores(as) e estudantes.

\begin{abstract}
Eu lembro que nós tínhamos uma coartisenti que tinha um Terreiro de Santo e que, por isso, não ia nas aulas nas sexta-feira e a gente descobriu porque ela não ia na aula e, por isso, criávamos uma relação com ela e sabíamos porque ela não gostava de falar de alguma coisa. Com cada coartisenti, criávamos uma relação e, por isso, entendíamos muitas coisas deles. (SILVA, Maria de Fátima: artisenti. Roda de conversa em 7 de mar. 2020)
\end{abstract}

Esse excerto reforça a importância da percepção dos objetos e das pessoas no reconhecimento do mundo vivido, conforme descrito por Merleau-Ponty (2006, p. 5): “A cada momento, meu campo perceptivo é preenchido de reflexos e impressões[...]. Essa construção constante permite que eu me faça e refaça constantemente, construindo e reconstruindo a minha visão e percepção do mundo.” Porém, para conceber essas experiências, é preciso que o indivíduo se perceba como humano inconcluso, sempre se fazendo, como ser um construtor de experiências simbólicas que dão sentido à sua vida a partir do lugar, cultura e tradição que vive.

Quando os(as) estudantes se percebiam dentro desse contexto, eles se constituíam como seres capazes de modificar a sua vida e a dos(as) demais que estavam participando do processo junto com eles(as): cresciam em humanidade a cada dia. Por isso, essas experiências proporcionavam uma interação de conhecimentos que não tinham um único dono e, portanto, eram mais bem socializadas por todos(as) os(as) envolvidos(as). Não raro, falavam com o coletivo, sem perder a diversidade e a liberdade de se exprimir como pessoa. Guardavam o jeito de ser, valorizado por contar sua vida, suas experiências e por obter solidariedade de cada qual.

Ao relatar suas histórias, as pessoas se abriam para que os(as) outros(as) pudessem compreender um pouco a sua vida e suas atitudes. Como as pessoas que conviviam tinham vidas parecidas, estas se sensibilizavam e se viam no outro, criando coragem para relatar suas experiências e buscar possíveis mudanças que poderiam refletir em outra forma de encarar a vida, o seu eu e circunstâncias, por conseguinte, na construção de um futuro mais justo e humanizado como cidadã(os) de direito. Conforme dito por Carl Rogers: 
O facto de estes dois elementos importantes de nossa experiência parecerem estar em contradição assume talvez o mesmo significado que a contradição entre a teoria ondulatória e a teoria corpuscular da luz: demonstrar a verdade de cada uma das teorias e elas não deixam que nossa vida subjetiva, como também não se pode negar $o$ determinismo que é evidente na descrição objetiva dessa vida. Importa, portanto, que vivamos esse paradoxo. (ROGERS, 1981, s.d.)

E concluiu que aquilo que nos parece mais singular em cada pessoa é também o que há de mais universal para todas as outras. Quando a pedagogia permite a plena expressividade e liberdade de comunicação, recebe e aceita nossas singularidades desencontradas como formas adequadas de se poder ser com liberdade e sem repressão. Experiências essas que sempre proporcionarão uma negociação madura entre pessoas, ao mesmo tempo, singulares e completamente universais, que nos dá completude. Essa recriação na UPC foi um invento que trouxe à tona os maiores defeitos das chamadas educações ao gerar um ser universal idêntico sob grilhões, sem diferenças. MerleauPonty e Paulo Freire apontam um caminho de liberdade: um corpo próprio singular conviverá até o fim com a carnalidade universal que nos abraça em um universo instável, criativo, imersos e abraçados nos Sistemas Abertos ${ }^{5}$, no preciso sentido de Ilya Prigogine, recicláveis, que tiveram começo, mas não terão desfecho, no devenir dos Sistemas Abertos.

\section{Conclusão}

Ao buscar um outro modelo para a Educação de Jovens e Adultos, a Secretaria Municipal de Educação de Cuiabá rompeu com o paradigma existente. No antigo modelo ofertado, os(as) estudantes tinham uma educação tradicional, em que os(as) professores(as) ficavam na frente da sala de aula, professando o seu saber; e, os(as) estudantes ficavam sentados(as), um atrás do outro, apenas "recebendo" esse conhecimento. Essa "educação bancária", que Freire relata em seu livro Pedagogia do Oprimido (1987), continua sendo o marco na educação do nosso país. Hoje adquire também marcas do conhecimento embutido e formalizado por processos digitais, não menos exigentes em formação fabril, da linha de montagem. Agora engolidos pelas formas controladas pelas multinacionais e seus interesses conservadores, por outros tipos de clientelismo.

Então, quando é ofertada uma outra forma de fazer educação, na qual os(as) estudantes e professores(as) trocam conhecimentos em um sistema horizontal e cíclico, em que, às vezes, o professor ensina e o(a) estudante aprende e, em muitas outras, é o(a) estudante quem ensina e

\footnotetext{
${ }^{5}$ De acordo com Ilya Prigogine (1917-2003), define-se sistema aberto a partir da capacidade de determinar o grau com que novos sérvios podem ser adicionados e disponibilizados para o uso por uma variedade de sistemas diferentes, mas com uma mesma finalidade. A característica de um sistema aberto é quando existe a possibilidade de integração com os demais sistemas de forma a trabalhar em conjunto. Mas para essa integração funcionar as informações devem ser documentadas de forma clara.
} 
os(as) professores(as) e demais colegas que aprendem, ainda não se mostra aceito pelo sistema, pois as pessoas não entendem esse modelo e, por consequência, a sociedade também não o tolera. O risco sobre essa possibilidade é o do acesso de todos e todas na produção da sociedade, de suas formas de funcionamento e do direito de poder político, que gere a sociedade pública e justa.

A educação atual tem seu marco simbólico na transmissão de conhecimento e não na construção coletiva e socialização dos saberes. Muitos estudantes ajudam a perpetuar esse modelo, porque aprenderam que é assim que funciona, contudo, a maioria quer falar, quer ter o direito de expressar suas opiniões e pensamentos e almeja que estes sejam valorizados, porque se reconhece neles e sabe que suas palavras têm sentido no universo em que vive.

Educar para o pensamento e a criticidade, mas sobretudo para ação política organizada, será algo perigoso para quem está no poder. Pessoas críticas são vistas como perigosas, pois se reconhecem como ser de direito e passam a exigi-lo na construção de uma vida mais humana e justa. Por isso é tão difícil para as autoridades financiar um projeto como foi a UPC, visto que ela mexe com o status quo, o que já está posto, que funciona perfeitamente na manutenção repetitiva e mecânica, para quem não almeja mudanças, nem pessoas livres e diversas. Uma educação alienante serve, principalmente, para formar mão de obra escrava e/ou barata para o sistema capitalista, que, por sua vez, justifica os baixos salários e a exploração trabalhista em função da falta de qualificação. Ou, ainda, devido ao fato de que essa prática alienante e opressora leva as pessoas a se sentirem culpadas porque não terem estudado. Muitos(as) ainda não conseguem enxergar que foram furtados do direito de ter direitos. E o direito de não passar fome, de ter trabalho e saúde.

A dialética de tudo isso está no fato de que, sem a erradicação do analfabetismo, da diminuição da pobreza e da desigualdade, nunca se alcançará um país justo; sem justiça, este nunca será forte e, sem força da população que continuará sendo oprimida e roubada pelas nações mais poderosas.

\section{Referencias}

ARROYO, Miguel G. Outros Sujeitos, Outras Pedagogias. 2. ed. Petrópolis, RJ: Vozes, 2014.

ARROYO, Miguel G. Passageiros da noite: do trabalho para a EJA: itinerários pelo direito a uma vida justa. Petrópolis, RJ: Vozes, 2017.

ARROYO, Miguel G. Currículo, território em disputa. 5. ed. Petrópolis, RJ: Vozes, 2013.

BRANDÃO, Carlos Rodrigues. BORGES, Maristela Correa. O lugar da Vida: Comunidade e Comunidade Tradicional. CAMPO-TERRITÓRIO: Revista de Geografia Agrária. Edição especial do XXI ENGA - 2012, p. 1-23, jun., 2014. 
BRANDÃO, Carlos Rodrigues. O que é Educação Popular. São Paulo: Editora Brasiliense, 2006.

FREIRE, Paulo. Pedagogia do Oprimido. 17. ed. Rio de Janeiro: Paz e Terra, 1987

FREIRE, Paulo. A importância do ato de ler: em três artigos que se completam. São Paulo: Autores Associados: Cortez, 1989. (Coleção polêmica dos nossos tempos 4)

FREIRE, Paulo. Pedagogia da Esperança: um reencontro com a pedagogia do oprimido. (notas Ana Maria Araújo Freire). Rio de Janeiro: Paz e Terra, 1992.

FREIRE, Paulo. Pedagogia da Autonomia: Saberes necessário à prática educativa. São Paulo: Paz e Terra, 1996

FREIRE, Paulo. Pedagogia da indignação: Cartas Pedagógicas e outros escritos. São Paulo: Editora UNESP, 2000.

GADOTTI, Moacir. Educação Popular, Educação Social, Educação Comunitária: conceitos e práticas diversas, cimentadas por uma causa comum, p. 10-32. Revista Diálogos: pesquisa em extensão universitária. IV Congresso Internacional de Pedagogia Social: domínio epistemológico. Brasília, v. 18, n. 1, dez. 2012.

GADOTTI, Moacir. Por uma politica nacional de educação popular de jovens e adultos. 1. ed. São Paulo: Moderna; Fundação Santillana, 2014.

HESSEN, Joannes. Teoria do Conhecimento. Tradução: João Vergílio Gallerani Cuter; revisão técnica Sérgio Sérvulo da Cunha. 2. ed. São Paulo: Martins Fontes, 2003.

MALDONADO, Carlos(as) Alberto. UNEMAT: uma universidade para o $3^{\circ}$ milênio. Cáceres, MT: Editora Aguapé, 1995. (Coleção Inquieta Ação)

MATTOS, Antônio Marcos Passos de. Universidade Popular Comunitária: É possível uma outra educação? 2007, 181 f. Dissertação de Mestrado. Universidade Federal de Mato Grosso, Cuiabá, MT, 2007.

MERLEAU-PONTY, Maurice. Signos. Tradução: Maria Ermantina Galvão Gomes Pereira. 1. ed. brasileira. São Paulo: Martins Fontes, 1991.

MERLEAU-PONTY, Maurice. Conversas 1948. Organização e notas de Stéphanie Ménasé; Tradução: Fabio Landa e Eva Landa; Revisão de tradução: Marina Appenzeller. São Paulo: Martins Fontes, 2004.

MERLEAU-PONTY, Maurice. Fenomenologia da Percepşão. Tradução: Carlos Alberto Ribeiro de Moura. 3. ed. São Paulo: Martins Fontes, 2006.

MERLEAU-PONTY, Maurice. O Primado da Percepção e suas consequências filosófica. Tradução: Silvio Rosa Filho e Thiago Martins. 1. ed. reimp. Belo Horizonte, MG: Autêntica editora, 2017.

ROGERS, Carl. Tornar-se Pessoa. 2. ed. Tradução: Manuel Jose do Carmo Ferreira, Livraria Martins Fontes, Lisboa, 1981. 
SANTOS(AS), Boaventura de Souza; MENEZES, Maria de Paula. (orgs.). Epistemologia do Sul. São Paulo: Cortez, 2010.

SANTOS(AS), Boaventura de Souza. Gramática do Tempo: Para uma nova cultura política. São Paulo: Cortez, 2008.

SILVA, Loedilza Milicia da. Universidade Popular Comunitária: a importância da comunidade na Educação de Jovens e Adultos - 2020, 168 f. Dissertação de Mestrado. Universidade Federal de Mato Grosso, Cuiabá, MT, 2020.

SILVA, Maria de Fátima. Universidade Popular Comunitária (UPC), da solidão à solidariedade: tramas de educação e trabalho.2006. 118 f. (Dissertação) Mestrado em Educação Instituição de Ensino: Universidade Federal de Mato Grosso, Cuiabá, 2006.

STRECK. Danilo R. Práticas educativas e movimentos sociais na América Latina. Serie-estudos, Campo Grande, MS, n. 22, p. 99-111, jul./dez. 2006.

TSE, Lao. TAO TE CHING: O Livro do Caminho e da Virtude. Tradução: Mestre Wu Jyn Cherng Sociedade Taoísta do Brasil. Disponível em: http://www.taoismo.org.br. Acesso em: 10 mar. 2020

\section{Dados fornecidos por agências governamentais:}

CME. Conselho Municipal de Educação. Resolução nº 003/2002/CBÁ. 2002.

CUIABÁ. Câmara Municipal de Secretaria de Apoio Administrativo. Adesão à carta das Cidades Educadoras. Lei n. ${ }^{\circ} 3.979$ de 16 de novembro de 2000.

SME. Secretaria Municipal de Educação de Cuiabá. Plano de Desenvolvimento Institucional da Universidade Popular Comunitária de Cuiabá. 2003. 